\title{
On the use of optical remote sensing to assess phytoplankton biomass dynamics in the Pelagos Sanctuary (Ligurian-Provençal Sea)
}

\author{
M. Manca Zeichen ${ }^{\text {a,* }}$, M.G. Finoia a , P.J. Shaw ${ }^{\text {b }}$, I.S. Robinson ${ }^{c}$, V. Barale ${ }^{\mathrm{d}}$ \\ a National Italian Institute for Environment Protection and Research (ISPRA), Via Brancati 60, 00144 Rome, Italy \\ ${ }^{\mathrm{b}}$ International Centre for Environmental Science, Faculty of Engineering and the Environment, University of Southampton, Highfield, \\ Southampton SO17 1BJ, UK \\ ${ }^{c}$ Ocean and Earth Science, National Oceanography Centre, Southampton, University of Southampton, Waterfront Campus, European Way, \\ Southampton SO14 3ZH, UK \\ d Institute for Environment and Sustainability, Joint Research Centre, European Commission TP 272, 21020 Ispra (VA), Italy
}

\section{H I G H L I G H T S}

- A statistical approach to the analysis of the remotely sensed chl field is proposed.

- Historical series of ocean colour observations were analysed.

- A description of phytoplankton dynamics in a pelagic Mediterranean MPA is shown.

\section{A R T I C L E I N F O}

\section{Article history:}

Received 21 November 2016

Available online 7 March 2017

\section{Keywords:}

Marine Protected Areas

Ligurian Sea

Ocean colour

Phytoplankton biomass

Historical series

\begin{abstract}
A B S T R A C T
If Marine Protected Areas (MPAs) are to aid in protecting and conserving marine ecosystems in the face of extensive and severe impacts of human activities, underpinning scientific knowledge and understanding of MPAs are imperative. This study aims to describe and evaluate phytoplankton dynamics in a pelagic Mediterranean MPA (The Pelagos International Marine Mammals Sanctuary) in the northwestern Mediterranean Sea as a means to understand better the spatial and temporal distribution of basal ecosystem resources. Ocean colour data collected by orbital remote sensing (Sea-viewing Wide Field-of-view Sensor [SeaWiFS] data) were analysed to elucidate spatial and temporal variations in the concentration of chlorophyll-like pigments ( $c h l$ ). Mean chl images were generated for consecutive 10-day periods, to provide quasi-continuous coverage of the study area, combined with a Principal Component Analysis and analysis of a time series (1998-2004). The chl surface patterns traced seasonal upwelling events recurring annually, demonstrating the critical role of physical oceanography in sustaining the food web of the PelagosSanctuary. Phytoplankton blooms, however, differ in terms of peak timing, spatial distribution and chl concentration, due in part to the influence of broad-scale environmental factors that are beyond direct and regional control. Further research is needed to elucidate the relationship between the biomass of primary and secondary producers to understand better the implications of phytoplankton biomass distribution in space and time for charismatic and protected biota such as cetaceans.
\end{abstract}

(c) 2017 Elsevier B.V. All rights reserved.

\section{Introduction}

\subsection{Marine protection and the Mediterranean Sea}

There is little doubt that marine systems and their resources are under threat from human activities and that remedial actions are

\footnotetext{
* Corresponding author. Fax: +3906 50074228.

E-mail addresses: marta.mancazeichen@isprambiente.it (M. Manca Zeichen), mariagrazia.finoia@isprambiente.it (M.G. Finoia), P.J.Shaw@soton.ac.uk (P.J. Shaw), I.S.Robinson@soton.ac.uk (I.S. Robinson), vittorio.barale@jrc.it (V. Barale).

necessary. Actions to ensure that marine systems are conserved in the long term have been proposed (Secretariat of the Convention on Biological Diversity (CBD), 2012) and Marine Protected Areas (MPAs) have been widely implemented to achieve this aim (World Data Base on Protected Areas, WDPA, 2012). Through restrictions and controls on activities within specified areas, MPAs are deemed to have potential to protect natural resources whilst maintaining social and economic benefits, e.g. through ecosystem services, fishing and tourism (Secretariat of the CBD, 2008).

Due to its environmental, physical and biological diversity, and value to the nations along its coasts, the Mediterranean Sea has 
been subject to a series of initiatives to protect its marine resources (Abdulla et al., 2008). The geographic and climatic conditions of the north-western Mediterranean Sea, for example, play a vital role in the biological cycles of this entire near-coastal region (Astraldi et al., 1994, 1995). Specifically, the strong air-sea interactions trigger convection processes that can mix the entire water column and fertilise the photic zone with nutrients from deeper layers (Astraldi et al., 1994, 1995). This systematic fertilisation of surface waters supports high biological production, leading to a food web which includes fin whales, Balaenoptera physalus, and other marine mammals. The conservation value of this region was recognised by the establishment of the Pelagos International Sanctuary for Marine Mammals (Fig. 1) in 1999.

In order that MPAs such as the Pelagos sanctuary accomplish their aims, underpinning scientific knowledge and understanding are imperative. The spatial and temporal distributions of primary production are of particular concern; the seasonal cycles and their variability in space and time influence availability of basal resources that, in turn, determine the viability of higher predators (Notarbartolo di Sciara et al., 2008).

\subsection{The Pelagos sanctuary}

The creation of the Pelagos sanctuary (Fig. 1) stems from research conducted since the late 1980 s, which has identified the notable presence of cetaceans coupled with a diverse pelagic macrofauna community including tuna (Thunnus thynnus), swordfish (Xiphias gladius), sunfish (Mola mola), shark (Alopias vulpinus, Prionace glauca, Charcarinus plumbeus, and Charcarodon charcarias) and giant devilray (Mobula mobular). With regard to cetaceans, striped dolphins (Stenella coeruleoalba), sperm whales (Physeter macrocephalus) and fin whales (Balaenoptera physalus) are abundant within the Pelagos Sanctuary (Gordon et al., 2000; Clark et al., 2002). Other frequently-occurring species include Cuvier's beaked whale (Ziphius cavirostris), the longfinned pilot whale (Globicefala melas), Risso's dolphin (Grampus griseus), the common dolphin (Delphinus delphis), and the coastal bottlenose dolphin (Tursiops truncatus) (Notarbartolo di Sciara, 1994). Populations of dolphins within the Pelagos sanctuary may reach several tens of thousands, and a thousand whales may also be present (Bérubé et al., 1998). Cetaceans are endangered variously by entanglement in floating nets, pollution, and also by prey depletion due to overfishing (Aguilar, 2000; Gordon et al., 2000).

\subsection{Physical oceanography of the Ligurian Sea}

The Mediterranean Sea could be considered as a deep sea and has in general very feeble tides. The surface current systems in the Mediterranean basin are strongly influenced by the surface water flow from the Atlantic into the Mediterranean (from the west to the east) which forms gyres. The other important current in the Mediterranean is the vertical convection which allows the balancing of salinity and recycling of nutrients.

The northern portion of the western Mediterranean basin encompasses the Gulf of Lion and the Ligurian Sea, forming the Ligurian-Provençal basin (Fig. 1) which is separated from the Thyrrhenian Sea by the Corsica channel. The Ligurian-Provençal basin is influenced by atmospheric conditions in winter, caused by cold-dry north-western winds such as the Mistral and Tramontana, which induce strong air-sea interaction processes that cause water evaporation and heat loss (Batisse and de Grissac, 1995). These processes cause the surface layer to become dense enough to sink, producing the Deep Water Formation (DWF) (below ca. 800-1200 m), notably in the Gulf of Lion region (Gascard, 1978), generating a cyclonic gyre (Bunker, 1972) (Fig. 1). The general circulation within the Ligurian-Provençal basin follows a cyclonic gyre, being a part of the general cyclonic circulation of the Western Mediterranean Sea, due to the presence of baric depressions which produce an intensification of the coastal currents towards the west. The gyre shows a seasonal cycle; its extension and intensity are related to the seasonal variations of the atmospheric forcing (Esposito and Manzella, 1982; Dagnino, 1978; Doglioli et al., 2004; Manzella, 1983). This hydrodynamic feature involves the two main Mediterranean water masses, i.e. the surface water of the Modified Atlantic Water (MAW-0-150/200 m) and the deeper Levantine Intermediate Water (LIW-150/200-400/600 m). In the coastal area, water coming from both the western (West Corsica Current, WCC) and eastern (Tyrrhenian Current) sides of Corsica join together to the north of the island in the Ligurian coastal current that flows westwards alongshore, roughly following the bathymetry as far as the Gulf of Lion and the Catalan Sea Astraldi and Gasparini (1986) and Astraldi et al. (1994). In winter, the flow in the Corsica channel increases, whereas the flow on the western side of Corsica remains unchanged during the whole year (Astraldi and Gasparini, 1986; Buffoni et al., 1997).

The main current comes from east and pushes the surface waters towards the west with a mean speed of $0.25-0.4 \mathrm{~ms}^{-1}$ (De Maio et al., 1975; Stocchino and Testoni, 1977). A branch of this current, at the latitude of Hyères islands (Fig. 1), runs initially towards the south and then towards the east as far as the coast of Corsica island. Here, after following the coastal profile, it interacts with a Tyrrhenic current originating from the south/south-east which flows between Corsica island and Capraia island (Corsica channel), forming a new current which moves north. The profiles of temperature and salinity within the Eastern Ligurian shelf show that stratification occurs from May to October. From November to April the thermocline is generally absent (Astraldi and Manzella, 1983; Astraldi and Gasparini, 1986).

The cyclonic circulation in the Ligurian Sea occurs in its central zone, associated with vertical diffusion due to wind forcing, produces nutrient enrichment of the upper mixed layers.

These processes induce the surface layer to become dense enough to sink, producing the Deep Water Formation (DWF) which also contributes to nutrient enrichment (Nezlin et al., 2004).

\subsection{Geomorphology and productivity of the Ligurian-Provençal basin}

The Ligurian-Provençal basin is characterised by a very narrow continental shelf and widens along the plains of Tuscany and Corsica. The coasts which surround the Pelagos Sanctuary are mostly rocky; only the eastern coasts of Corsica and Tuscany comprise plains with sandy beaches. The Pelagos Sanctuary includes several islands, i.e. Corsica, (northern) Sardinia, Hyères Isles, the Ligurian Islets, the Tuscan archipelago (Islands of Capraia, Gorgona, Elba, Giglio Giannutri and Montecristo) and the islands of the Bonifacio strait (Fig. 1). The bathymetry of the Ligurian-Provençal basin ranges offshore from $2500 \mathrm{~m}$ to $2700 \mathrm{~m}$. The rocky coasts have submarine canyons and caves which generate both geomorphological and hydrological features. These geomorphological characteristics house a variety of habitats and biocoenotic assemblages (Azzellino et al., 2008). The hydrological features are generated by the physical processes occurring within the basin which form vertical front systems, thus allowing the nutrients to rise to the surface and underpin primary production. The cyclonic Ligurian current which, together with the permanent front, is the prevailing current within the sanctuary, favours the occurrence of high rates of primary production within the region encompassing Ligurian-Provençal basin and the Gulf of Lion (Jacques, 1990), thus allowing a rich pelagic biodiversity. These phenomena are also enhanced by the Ekman pumping which induces upwelling within the 


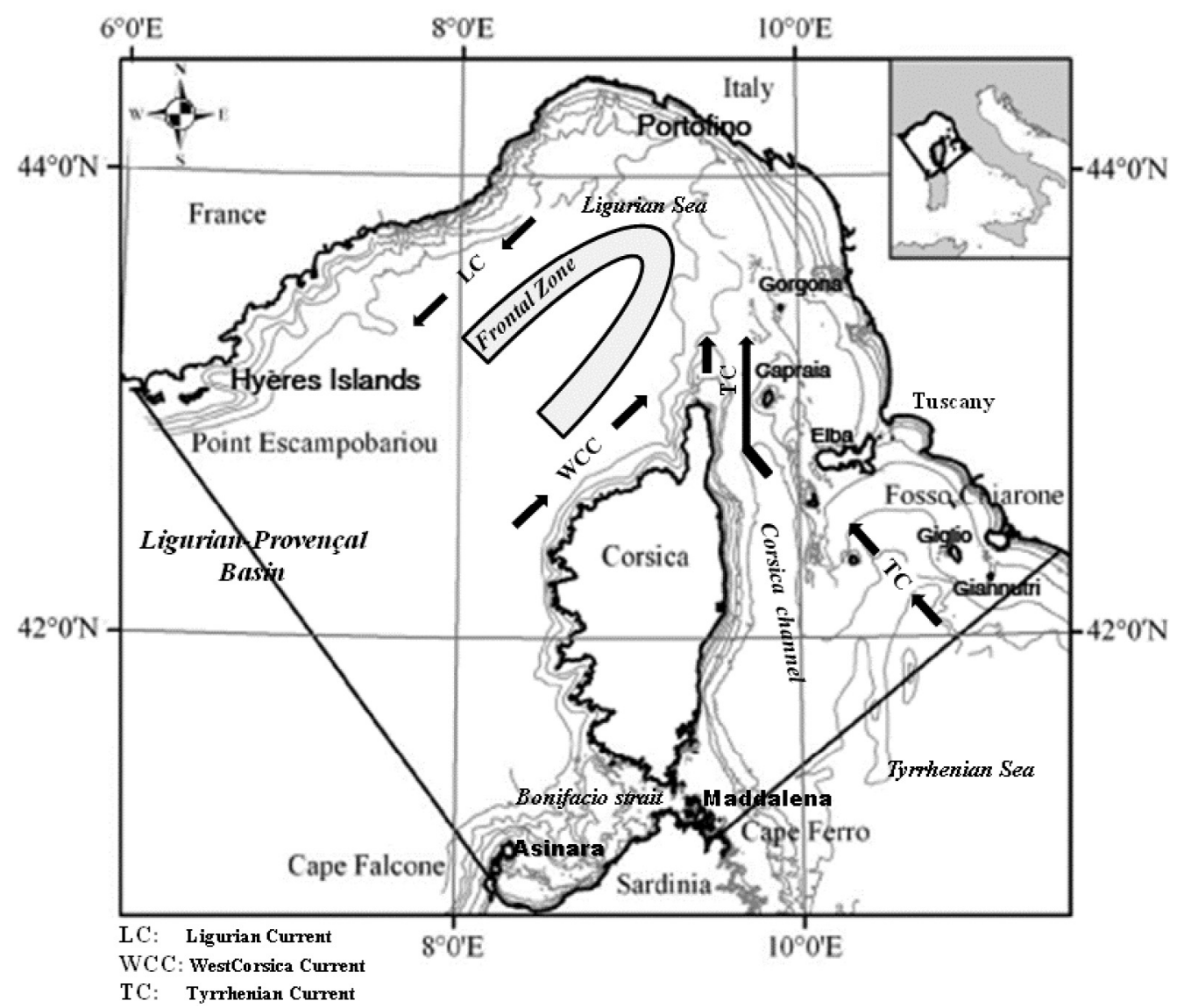

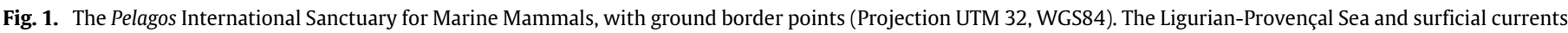
circulation scheme within Ligurian-Provençal Sea.

cyclonic feature (Andersen and Prieur, 2000). Such productivity maintains high mesopelagic zooplankton biomass consisting mainly of Meganyctiphanes norvegica euphausiid crustaceans (krill) (Orsi Relini et al., 1998); elevated zooplankton concentrations attract various upper-trophic level predators, including krill-eating whales. The northern krill is seasonally abundant and it represents the primary food source on which Mediterranean fin whales feed in summer (Forcada et al., 1996).

\subsection{Aims of the study}

Given the importance of primary production in underpinning the ecosystem in region of the Pelagos Sanctuary, it is critical to understand the variability and distribution of phytoplankton biomass on a meaningful temporal and spatial scale. Extensive phytoplankton bloom episodes recur annually in the region, but differ markedly in terms of the magnitude of chl levels from year to year, chl being the principal indicator of phytoplankton biomass and the most suitable and tested parameter easily retrieved by Remote Sensing. Such data on phytoplankton biomass dynamics, retrieved synoptically from satellite data, are of the outmost importance in order to understand better the baseline of ecological relationships within the Pelagos Sanctuary, thus contributing to more effective management of this unique MPA. This study aims, therefore, to elucidate phytoplankton biomass dynamics in the north-western Mediterranean region by means of ocean colour data time series, collected by orbital remote sensing. The availability of an archive of Sea-viewing Wide Field-of-view Sensor (SeaWiFS) data enabled derivation of chl (McClain et al., 2004) as a phytoplankton biomass index. The surface patterns appearing in the SeaWiFS imagery were used to trace the seasonal sequence of events that supports the ecology (Gordon et al., 2000; Clark et al., 2002; Notarbartolo di Sciara, 1994) of the Pelagos Sanctuary.

\section{Materials and methods}

Data processing and analysis have been carried out to generate and interrogate $\mathrm{chl}$ maps for consecutive 10-day periods, to ensure quasi-continuous coverage of the area of interest. This approach aimed first to produce a graphical representation of the time series of chl maps, in order to investigate the $c h l$ trend and its temporal fluctuations, and secondly, to interrogate data thus acquired using appropriate statistical analyses

\subsection{Satellite data processing}

The SeaWiFS data set used to monitor the evolution of the chl field in the study area was collected with high spatial resolution for 1998-2004. Concentrations of chl were derived using the bandratio empirical algorithm OC4v4 (O'Reilly et al., 2000), with revised numerical coefficients (Mélin et al., 2000).

The $c h l$ images were co-registered and projected using the functionality of SeaDAS image analysis package. All single images were re-mapped on a rectangular projection (cylindrical equidistant) grid covering the Mediterranean basin (coordinates at the upper left and lower right corner pixels in the grid were $46.0^{\circ} \mathrm{N} 6.5^{\circ} \mathrm{E}$ and $30.0^{\circ} \mathrm{N} 36.5^{\circ} \mathrm{E}$ respectively), with a pixel resolution of $2 \mathrm{~km}$. Composite (decadal) mean fields were derived from the re-mapped images by averaging. A sub-scene, bounded by $44.54^{\circ} \mathrm{N} 5.80^{\circ} \mathrm{E}$ (upper left) and $40.80^{\circ} \mathrm{N} 11.52^{\circ} \mathrm{E}$ (lower right), was then extracted from each chl composite image, and masked with a polygon reproducing the boundaries of the Pelagos Sanctuary. For the series of masked decadal composite maps of the chl field, each image is identified by year and by the related Julian Days, to say the start-end Ordinal dates of the decadal (10-day) period. 
Further details on satellite data processing are available in Appendix A.

\subsection{Statistical analyses}

In order to characterise the algal blooms appearing in the decadal composite maps, a statistical analysis was performed on the masked sub-scenes, which consisted of 213 rows and 238 columns, covering the area of the Pelagos Sanctuary. Each row was then considered as a single multivariate observation. A second mask was created in order to discriminate between cloud and land pixels, which were instead all set to a value of 0 .

Principal Component Analysis (PCA; Johnson and Wichern, 1982) was used to represent the chl trend, according to two dimensions over time (i.e. the temporal behaviour of the first two components provided by PCA). The statistical properties of the first extracted component (PC1), were also represented in timeline form of box-plots, covering a seven year period, from 1998 to 2004 , and describing the main statistical features of the related distributions.

Furthermore, in order to prove and explain differences among the various matrices (images), Energy Distances (E-distances) and Energy Statistic Test for Equal Distributions (Szekely and Rizzo, 2004, 2013) were computed and applied on the satellite data. The main objective was to give a measure to the detected distance between two matrices and checking the existence of significant differences between pairs of $c h l$ maps (i.e. verifying differences in the chlorophyll data distributions).

The comparisons were carried out between images referred both to the same decadal periods throughout the 7 years considered and between particular decadal periods within the same year.

The E-distances were computed from the original pooled data, with single values stacked in a comprehensive matrix, where each row was considered as a multivariate observation. The first 213 rows of the data matrix thus obtained were referred to the first decadal period analysed, the next 213 rows to the second one and so on. Thus, the dimension of the original matrix was 53676 rows ( 213 rows $\times 252$ decades) and 238 columns. The procedure to calculate the E-distance between two clusters, $C_{i}, C_{j}$ of size $n_{i}, n_{j}$ respectively, was that proposed by Szekely and Rizzo (2013).

In order to consider only significant comparisons, i.e. those for which the value of E-distance was significantly high, the p-level was modified using Bonferroni's correction. The test was implemented by non-parametric bootstrap (approximate permutation test), with $m$ replicates.

Appendix B reports more details on the adopted procedures.

Finally, a time series analysis was performed. The factor scores calculated on the PC1 were analysed by means of historical series techniques (Bee Dagum, 2002). In particular, the time series was decomposed in its additive components, such as trend, seasonality or cycles and residuals, based on an additive model.

All statistical tests were performed by using RGUI free software (R Development Core Team, 2004).

\section{Results}

\subsection{Surface features}

The chl maps (Fig. 2) show a marked space-time heterogeneity, particularly prominent (on a seasonal scale) in the Pelagos Sanctuary's north-west region. As shown by the sequence of panels (Fig. 2a), in general the spring bloom takes place at the end of winter, in March, (from the Ordinal dates 060-069), and continues through spring, until April (to the Ordinal dates 111-120). The most notable spring phytoplankton bloom occurred in 1999. At the end of March the 1999 bloom almost completely covered the western area of the Sanctuary. In contrast, spring 1998 showed the minimum bloom extent. Summer months and in particular July and August (Fig. 2b), show lower chl values (corresponding to Julian Days 182-244).

During the Autumn season, and in particular in November and December (Fig. 2c), high interannual variability is highlighted, due to the strong discontinuity in the resumption of algal cycles, which can be anticipated in early December, otherwise usually occurring at the end of January.

\subsection{Statistical analysis}

The matrix on which PCA has been applied, contained the data of the $36 \times 7=252$ (10-day) periods. The first dimension extracted (PC1), to say the first component of the whole variability inside the data matrix as provided by the PCA, explains up to $33 \%$ of the total. PC2 describes only $19.4 \%$ of the total variability. It is characterised by a highly irregular trend and thus seems to be influenced by the presence of disturbed signals, probably due to the cloud coverage.

We therefore focused our attention only on the first component.

The overall results, in the form of graphical representation of the PC1 data, are shown in Fig. 3, where the temporal variations of the PC1 scores are reported as a sequence of box plots. By an inspection of these multiyear diagrams, we can observe several peaks corresponding to winter-spring months, as opposed to a more regular pattern in the summertime, usually from the 15 th to 25 th (10-day) period of the year. We can conclude that PC1 changes are to be referred mainly to the variations in the chl field, since they seem to express the seasonal trends of chlorophyll showing peaks usually during winter-spring months.

In particular, positive peaks should indicate high chl values, associated with algal blooms affecting the whole area of study (Fig. 2a), whereas negative peaks should to be reported as images distorted by cloud cover. Conversely, values regularly close to zero seem represent a stagnation of the algal cycles, as highlighted during summer months by the corresponding satellite images (Fig. 2b).

The onset of the blooming period is not regular in time since it varies from winter to spring, i.e. from decadal period 3-4 (in 1998, 2001, 2002 and 2003) to 6-7 (in 1999, 2000 and 2004). In general, an early onset is followed by repeated oscillations, at the monthly scale, of the statistical indicators (e.g. in 1998 and 2004), as if blooms would arise successively and repeatedly throughout spring. Conversely, a late onset is followed by a single large bloom (e.g. in 1999), lasting for the entire spring season. During autumn and, in particular, the last decadal periods of the year, PC1 values could show peaks corresponding to the month of December (as in the years 1998, 2000,2004), in some cases also in November (1999, 2001).

Following the winter-to-spring blooming season, the statistical indicators show a period of low variability, in all years considered. Starting from decadal periods $26-27$, when the stratification is broken up by the changing meteorological conditions of early autumn, analysis shows again a series of successive oscillations, at the monthly scale.

The use of multivariate E-statistic for testing equal distributions proves that satellite maps, even if they appear quasi-identical, differ, based on the analysis of the distance which highlights in quantitative terms the differences.

The results of the E-statistic for testing equal distributions (Table 1), show that the chl levels registered during spring (e.g. Julian Days 070-079) and autumn (e.g. Julian Days 294-304) of 1999 were significantly higher than in all other years (difference highly significant: $p<0.01$ ). Analysis shows an alternation of significant differences corresponding to November and December. 

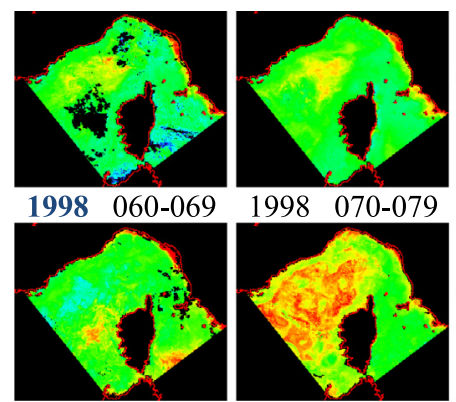

$1998 \quad 070-079$

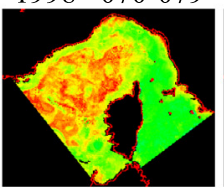

$1999 \quad 060-069$

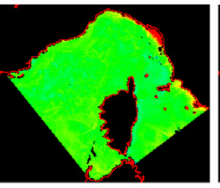

1999 070-079

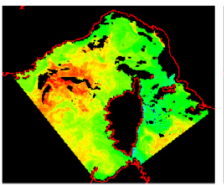

$2000 \quad 071-080$
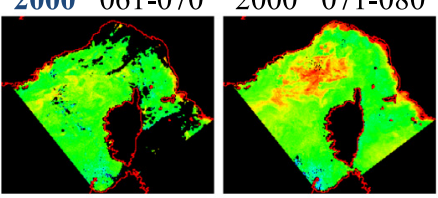

$2001 \quad 060-069$

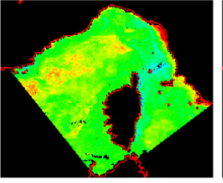

$2002 \quad 060-069$

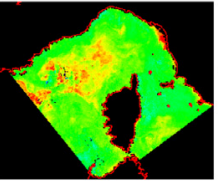

$2003 \quad 060-069$

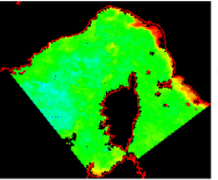

$2004 \quad 061-070$
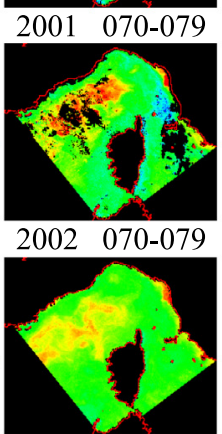

$2003 \quad 070-079$

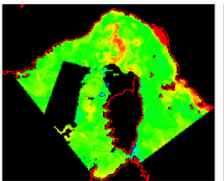

$2004 \quad 071-080$
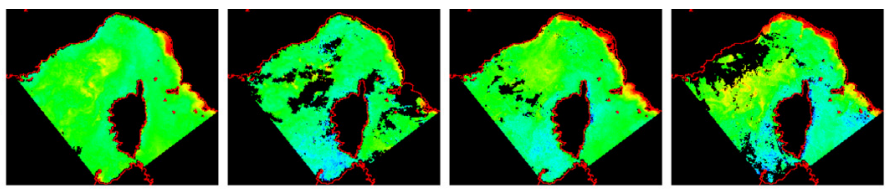

$1998 \quad 080-090$

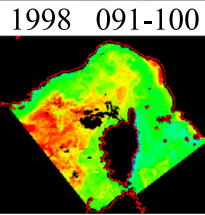

$1998 \quad 101-110$

$1998 \quad 111-120$

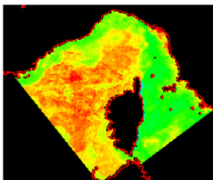

1999 080-090

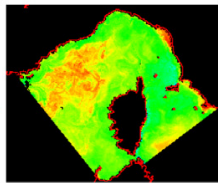

1999 091-100
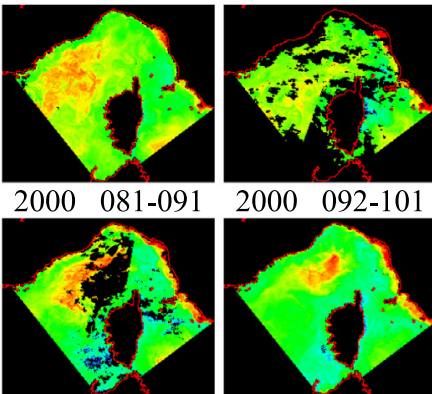

$2001 \quad 080-090$

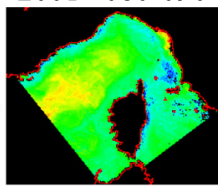

$2001 \quad 091-100$

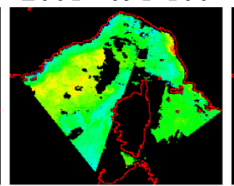

$2002 \quad 080-090$
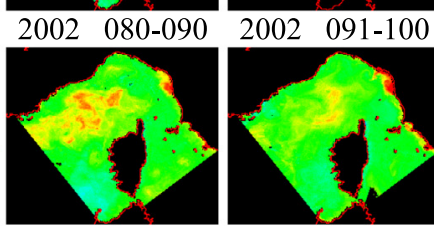

$2003 \quad 080-090$
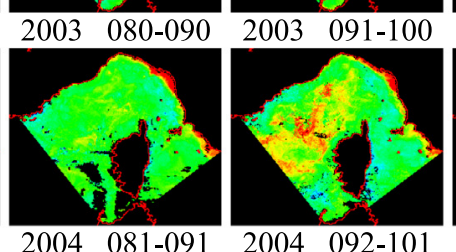

2004 081-091

$2004 \quad 092-101$
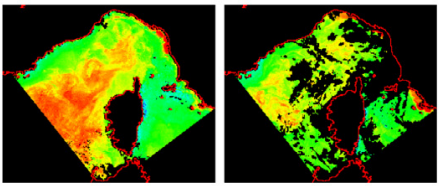

1999 101-110

1999 111-120
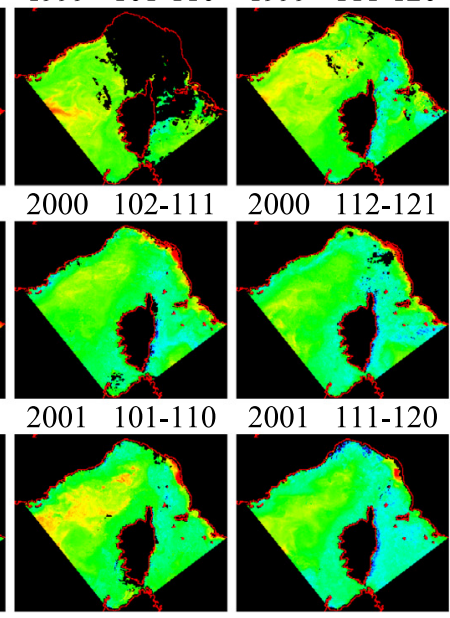

$2002 \quad 101-110$

$2002 \quad 111-120$
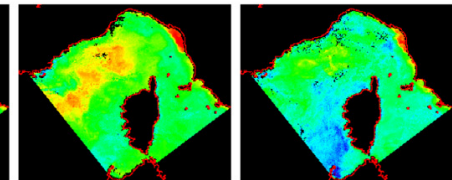

$2003 \quad 101-110 \quad 2003 \quad 111-120$
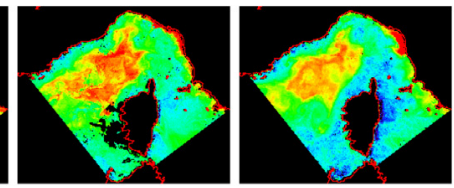

$2004 \quad 102-111 \quad 2004 \quad 112-121$

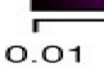

O. 1

Chl [ $\left.\mathrm{mg} \mathrm{m}^{-3}\right]$

Fig. 2a. SeaWiFS-derived chl $\left[\mathrm{mg} \mathrm{m}^{-3}\right]$ within the Pelagos Sanctuary (1998-2004) during March/April.

This could be ascribed to a restart of the algal cycles as early as December.

The comparison of spring data (e.g. Julian Days 070-079) suggests that the chl behaviour can be considered homogeneous (not significantly different: $p>0.01$ ) over this period, particularly for the years 2001 and 2002.

Table 2 provides examples of comparisons carried out for successive images related to the same seasonal period, in the same year, i.e. the decadal periods of spring (e.g. from Julian Days 060-069 to 101-110) and the decadal periods of autumn (e.g. from 294-304 to 355-365) during the years 1999 and 2004. In 1999, the $E$ values show a significant increase from Julian Days 060-069 to $070-079$. Following this rise, the levels of E-distance values were constantly high during the following three decadal periods. Conversely, rather erratic fluctuations appeared after the abrupt change from Julian Days 294-304 to 305-314. During 2004, the Edistance values show significant increase $(p<0.01)$ in chl levels from Julian Days 060-069 to 091-100
The use of E-distance statistics was aimed at clarifying the chlorophyll field behaviour during the year and, in this sense, has proved the seasonality of chlorophyll trends, highlighting particular situations that may occur and which demonstrate high inter-annual variability. However, it has not provided any insight to the comprehensive behaviour of the system in terms of the overall trend (increase or decrease) of chlorophyll in the entire period covered by the observations (1998-2004).

In order to explore the chlorophyll variability in a single glance throughout the years, trying to identify the different sources of variation, Time Series Analysis was applied to PC1 factor scores.

The purpose of the analysis of time series data is to recognise periodic changes (seasonal), trend (increasing or decreasing), and random fluctuations which do not correspond to the seasonality.

The time series of PC1 factors scores was broken down into components (Fig. 4). In the first top diagram the complete series, as it appears, is reported (Panel A). 


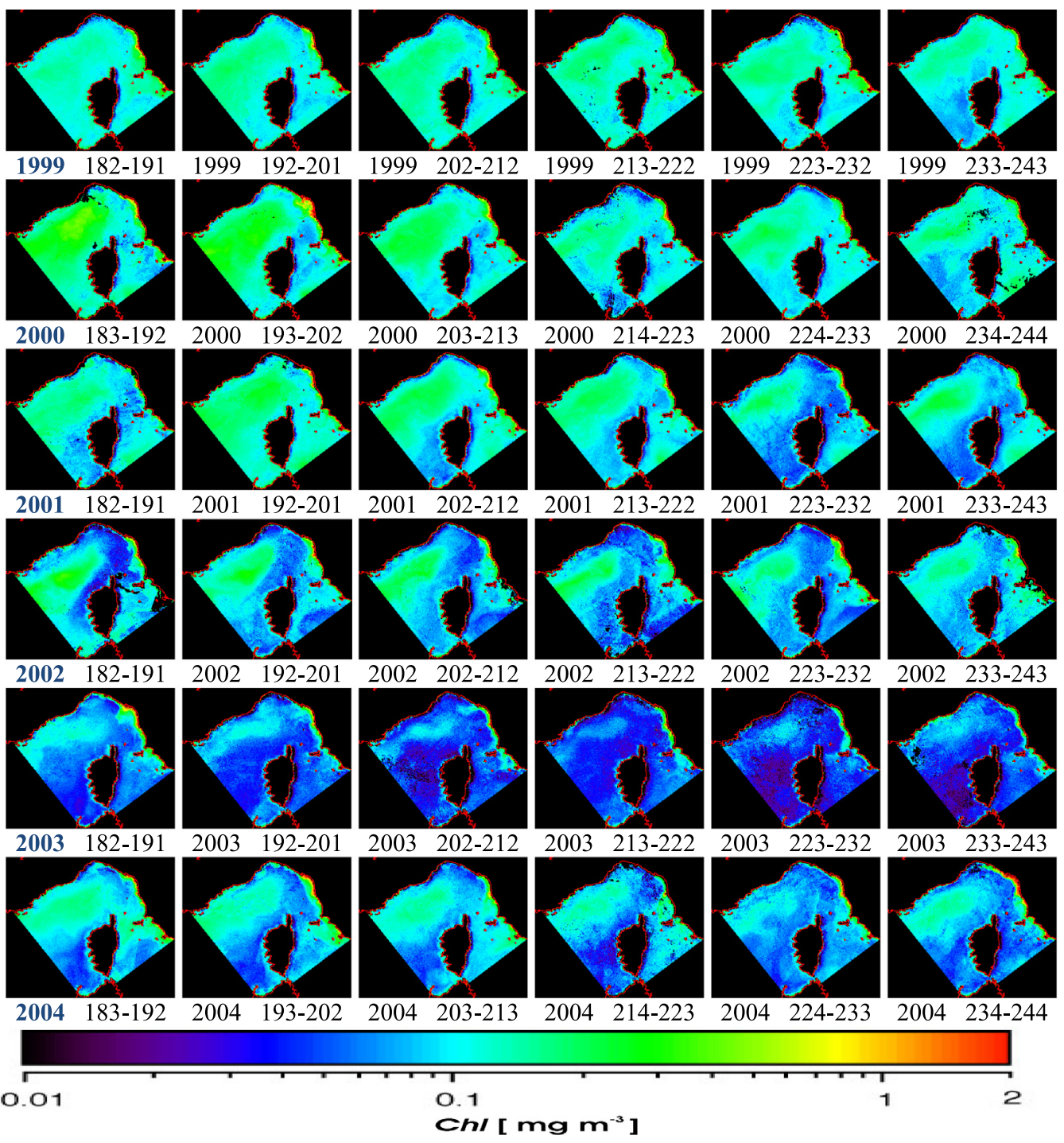

Fig. 2b. SeaWiFS-derived chl [ $\left.\mathrm{mg} \mathrm{m}^{-3}\right]$ within the Pelagos Sanctuary (1998-2004) during July/August.

In the second diagram (Panel B) the main periodic component (seasonality) has been separated. The phytoplankton blooms occurring between decades 8 and 9 (between March and April), are easily identified. During wintertime, chlorophyll minimum values are evident, due to the inactivity of the algal cycles.

The third diagram shows the multi-year tendency of the time series (Panel C): it would be very difficult to identify this trend watching only the raw data. We can observe a general decrease from the 1998 to the 2004. Maximum values are to be referred to 1999 and a successive decrease of the PC1 scores leads us to the minimum values in 2003. In 2004, the system seems to increase again.

The last diagram (Panel D) shows all the variations of the series that are not due to either the trend or seasonality, but represents the "remainders". There is a periodicity in the "remainders" which does not coincide with the seasonal one, it has the shorter periods and should depend on phenomena that occur in a shorter time scale. In other words this analysis allowed us to detect the effects on the chl field of processes acting on time period of days to weeks, of meteorological kind - wind, rain, storm events, etc. - but also the effects of hydrological phenomena such as freshwater inputs from rivers, local current framework, water column stability changes and water masses dynamics, etc.

\section{Discussion}

This study has elucidated the phytoplankton biomass patterns within the Pelagos Sanctuary by means of remotely-sensed ocean colour imagery, highlighting the spatial and temporal recurrence and inter-annual variability of chl. Statistical analysis of the remotely sensed $c h l$ field has been applied, enabling visualisation of the chl trend within the entire area of this MPA and over a multi-annual period. Furthermore, the analyses have highlighted recurrent and seasonal variations of $c h l$, with the presence of a marked peak of biomass in spring.

In the study area, the low chl values that occur in winter are followed by a notable bloom in spring. The patches of low chl are thought to be induced by the wind pattern prevailing in the northwest (e.g. the Mistral), causing convection processes that lead to surfacing of nutrient-rich (Millot, 1990). The general increase in chl values is likely related to nutrient supply, stimulated by the upper layer fertilisation that is due to intermittent vertical mixing and linked to the typical wind patterns of the winter period. The vertical mixing that prevents the blooming in winter also produces a marked increase in nutrient levels in the euphotic zone (Barale et al., 2008). Spring blooms are thereby favoured by the increase in solar irradiation and are thought to be triggered by the onset of stratification, which follows diminution of wind-induced mixing. 

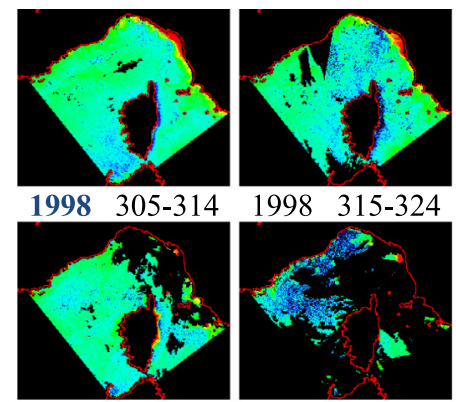

$1998 \quad 315-324$

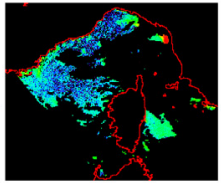

$1999 \quad 315-324$
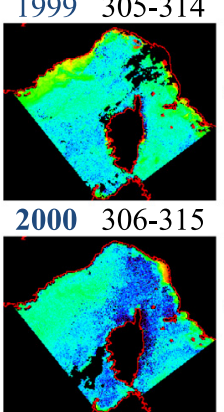

$2001 \quad 305-314$

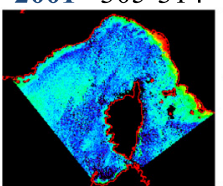

$2002 \quad 305-314$

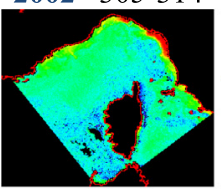

$2003 \quad 305-314$

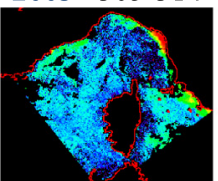

$2004 \quad 306-315$
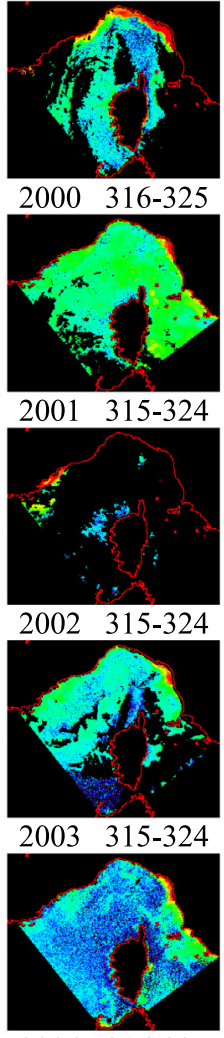
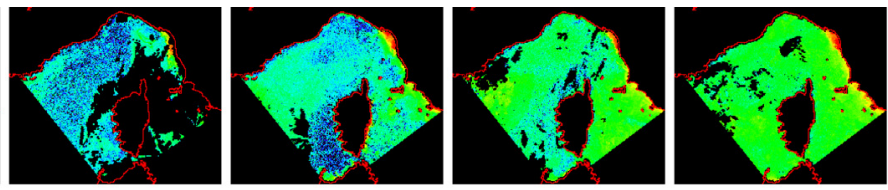

$1998 \quad 325-334$

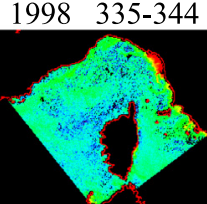

$1998 \quad 345-354$

$1998 \quad 355-365$

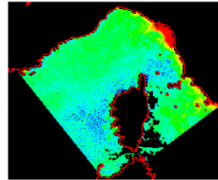

$1999 \quad 325-334$
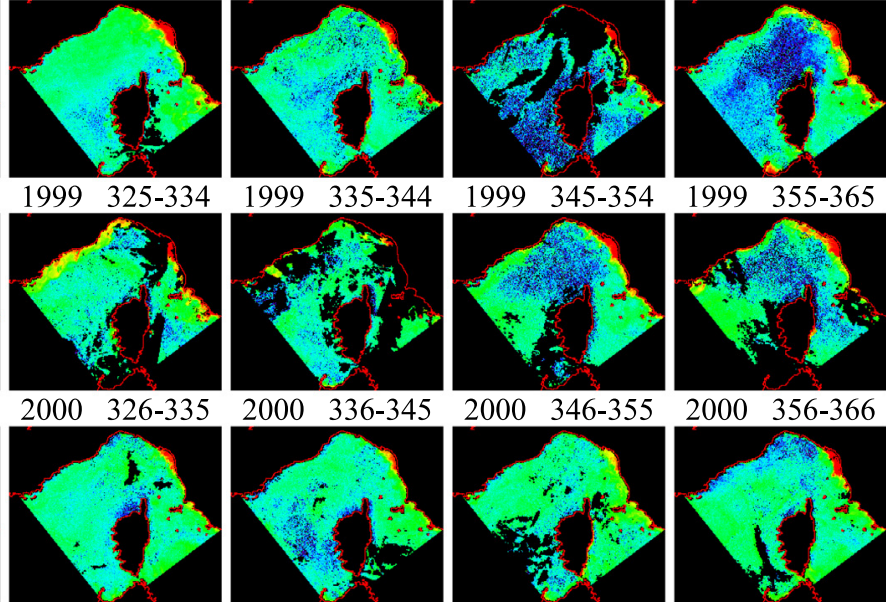

$2000 \quad 336-345$
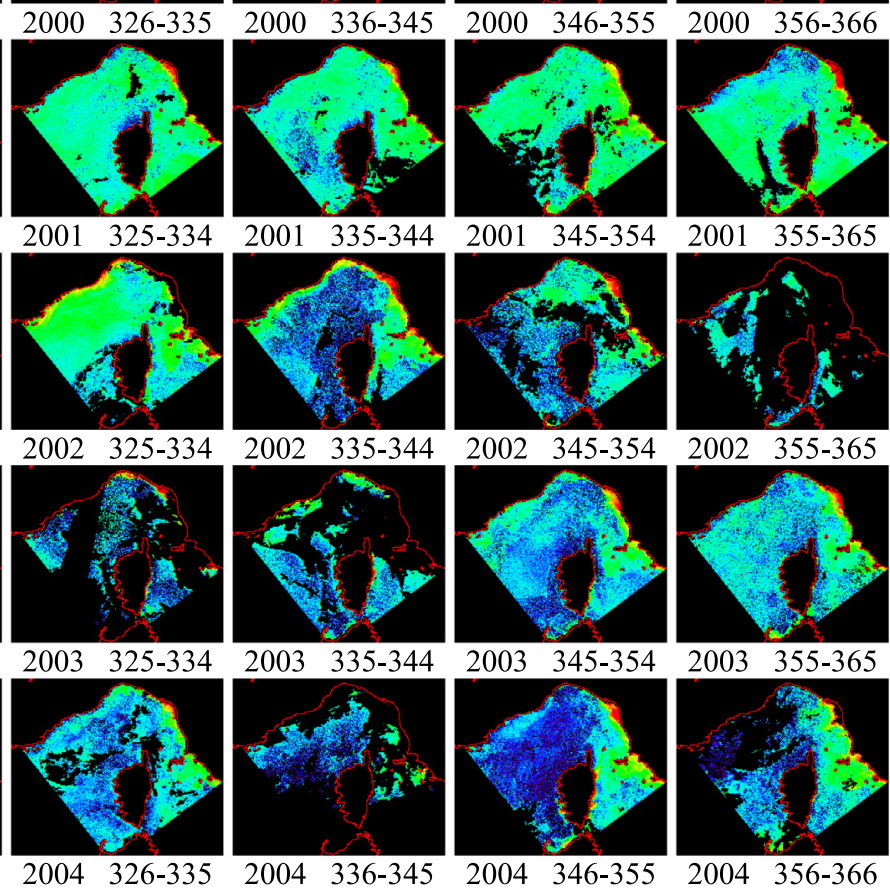

$2004 \quad 346-355$

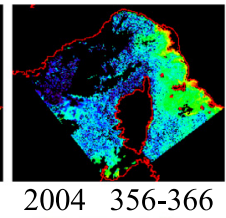

O. 01

O. 1

Chl [ $\left.\mathrm{mg} \mathrm{m}^{-3}\right]$

Fig. 2c. SeaWiFS-derived chl $\left[\mathrm{mg} \mathrm{m}^{-3}\right]$ within the Pelagos Sanctuary (1998-2004) during November/December.

Nezlin et al. (2004) ascribed the occurring of winter/spring blooms to the disruption of the seasonal thermocline, caused by cooling and mixing in autumn: the more nutrients are entrained into the upper layers, the more intensive is the consequent spring bloom and higher the phytoplankton biomass.

Illumination and nutrient availability are the main limiting factors of phytoplankton biomass development, whereas sea temperature affects the growth rate of phytoplankton: the maximum rate of growth doubles for approximately every $10{ }^{\circ} \mathrm{C}$ increase in temperature (Harris, 1984).

Although the bloom patch was sustained throughout summer and autumn, in summer the size of the patch and level of chl was diminished. This pattern corresponds to the summer chl minimum, which occurred in a period when stratification prevents the replenishment of nutrient levels in the euphotic zone by upwelling of more nutrient-rich deeper water. The relatively constant and lower chl levels registered in summer (Fig. 2) are in good agreement with previous research on the Western Mediterranean (Margalef, 1985; Arnone, 1994; Nezlin et al., 2004).
The low chl values observed during summers are thus likely the combined result of (1) the primary producers exhausting the nutrients made available by the wind-driven vertical mixing, and (2) grazing by secondary consumers. The growing biomass of secondary consumers such as euphausiids in summer, in turn, renders the north-western Mediterranean basin a preferred feeding ground for large marine mammals, such as the fin whale Balaenoptera physalus (Barale et al., 2002).

The decrease of chl observed in spring from 1999 to 2003 within the Pelagos Sanctuary and the concomitant decrease of the algal bloom intensity that occurs in spring (Fig. 4) are in agreement with the decrease of average $c h l$ value found by Barale et al. (2008) in the whole Mediterranean basin. In temperate seas such as Mediterranean, the phytoplankton biomass is primarily influenced by nutrient availability (Cruzado, 1985). The decrease of chl observed in spring over 1999-2003 could have led to the reduction of the zooplankton population which consequently impacted the fin whale population, leading to its decrease within 

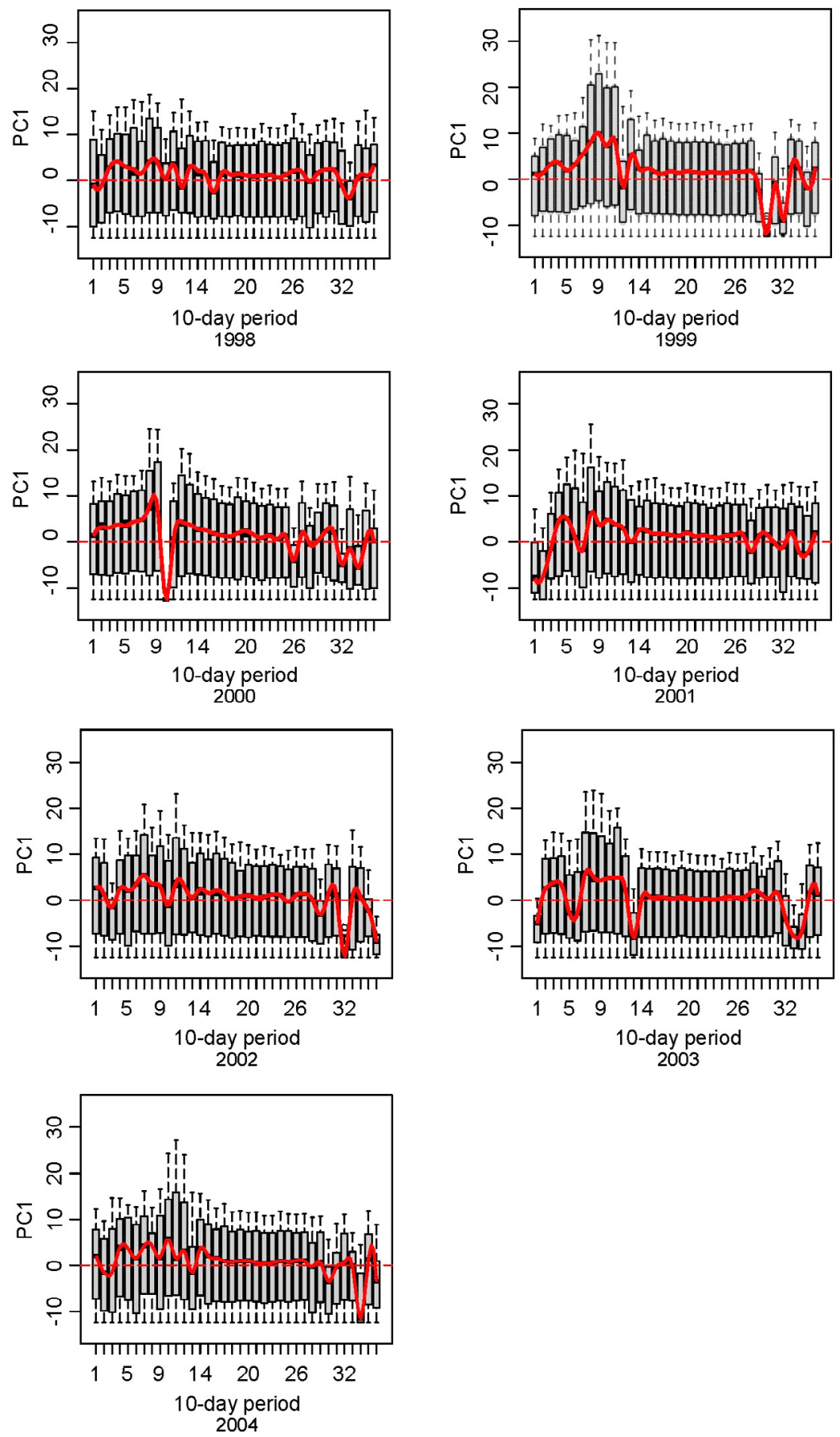

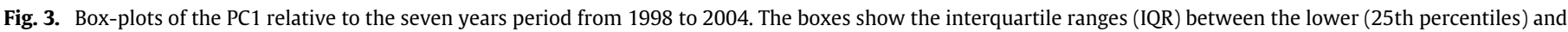

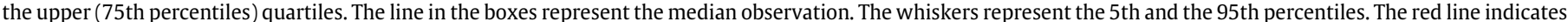

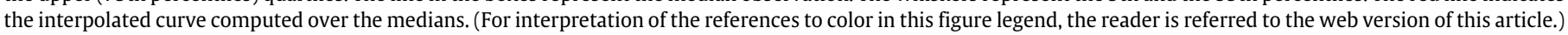

the Pelagos Sanctuary, as reported by Azzellino et al. (2012) during summers (June to September) between 1990 and 2007.

The spring bloom of 1998 was characterised by the lowest chl concentration observed during spring periods over the 7 years considered in this study and by a reduced spatial extent within the Pelagos Sanctuary. This occurrence could be attributed to the lack of deep convection in the Gulf of Lion in 1997 (Barale et al., 2008). The strong stability of the water column as recorded between 2000 and 2003 and the relatively low chl values observed in the time series (Fig. 4), are likely associated with abrupt changes in the mean temperature of the Mediterranean Sea (Béthoux et al., 1998). In fact, increases of $c a .0 .03{ }^{\circ} \mathrm{C}$ per year between 1985 and 2005 have been reported by Buongiorno Nardelli et al. (2007), thus increasing the likelihood of high density stratification and during periods with high $c h l$, rapid nutrient depletion in the upper layers. In particular, annual average Sea Surface Temperature (SST skin) registered in 2003 was ca.0.5 ${ }^{\circ} \mathrm{C}$, higher than the averages registered from 1985 to 2005 (Buongiorno Nardelli et al., 2007). The notable reduction in chl concentration and bloom magnitude recorded during spring 2003 could be ascribed to the same anomalous SST skin increase during 2003 in the western Mediterranean (Marullo and Guarracino, 2003). 


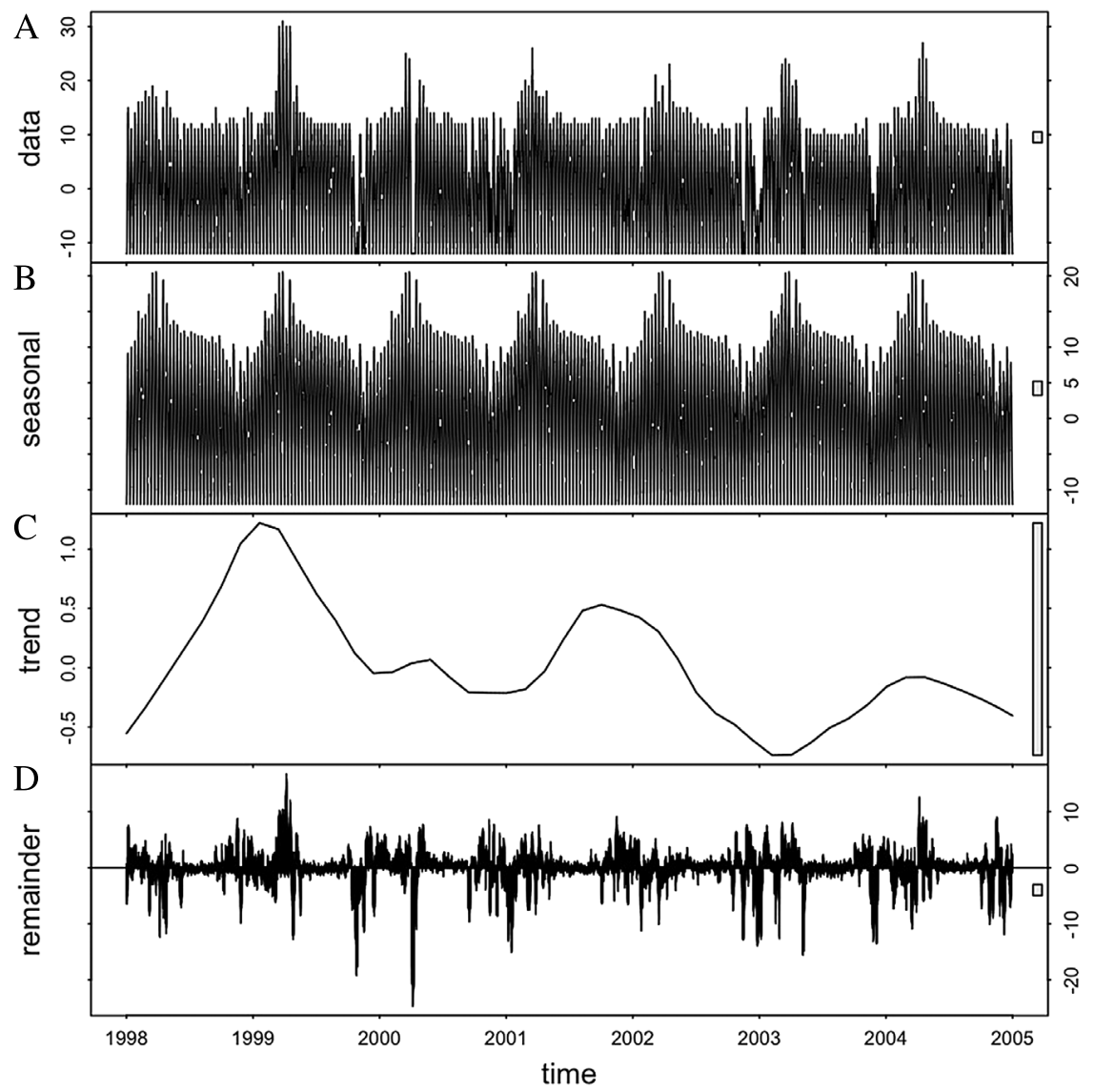

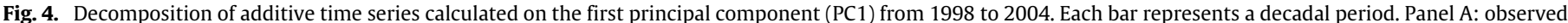
data. Panel B: seasonal variations. Panel C: inter-annual trend. Panel D: small scale periodical changes (residuals).

The chl values observed are influenced not only by environmental factors (e.g. wind-driven vertical mixing and its effects on nutrient supply), but also by biological factors. As a basal resource for the Pelagos ecosystem, phytoplankton biomass underpins grazing by secondary consumers such as euphausiid. The sustained and high levels of chl observed in the Pelagos Sanctuary region, therefore, demonstrate and reinforce the value of this area to marine life, particularly cetaceans. However, the influence of environmental factors on the timing, duration, concentration and distribution of $c h l$ as principal indicator of phytoplankton biomass highlight the importance of such factors for the continued viability of Pelagos as a rich and diverse area.

Analysis of climatological data collected by the Coastal Zone Colour Scanner (CZCS) (1978-1985; Barale et al., 2008) demonstrated that the lower wind speed and the consequently more stratified water column due to the colder SST had in the past occurred later in the year so that the spring bloom peaked in April (1978-1985) rather than in March (1998-2004). This phenomenon could be attributed to the greater difference between summer and autumn air temperatures, which leads to a more intense cooling of sea surface in the autumn and results in deeper autumn/winter mixing. This occurrence enriches the upper layers with nutrients, restarting the algal cycle in December as described by Colella (2007). This occurrence should give rise to the earlier onset of water column density stratification and favour occurrence of a winter bloom, as E-distance analysis carried on the PC1 data seems to confirm (Table 1).

Some key facets of MPAs can be effectively controlled by direct human intervention (Secretariat of the Convention on Biological
Diversity (CBD), 2012), notably access and exploitation. There are, however, key factors beyond the control of direct human intervention (e.g. weather and climate) that influence markedly the generation of basal resources that are essential to maintenance of the conditions necessary to sustain the diverse community of the Pelagos Sanctuary.

The Ligurian-Provençal basin accommodates the oceanographic processes and the inherent dynamics of the marine food-webs that support a productive and high value ecosystem of ecological importance. This region has been recognised through the creation and designation of the Pelagos Sanctuary (Notarbartolo di Sciara et al., 2008). The Pelagos Sanctuary region is high priority resource for Mediterranean cetaceans, supporting within the western Mediterranean several species of highly diversified zooplankton fauna which include macrozooplankton and Meganyctiphanes norvegica euphausiid crustaceans (Mediterranean krill) which constitutes a major prey in the marine trophic chain (Sardou et al. 1996).

Thus, the effective management of the Pelagos Sanctuary requires the protection of food web and ecosystems supporting the species and habitats that are present. In order to inform and support management of fin whale population, whose habitat preference is associated with pelagic areas in the central and western part of the Sanctuary (Azzellino et al., 2012), the oceanographic features that allow the euphausiid biomass to persist should be monitored (Notarbartolo di Sciara et al., 2008).

The study has demonstrated that remote-sensed data are instructive, especially for the stakeholders of the MPAs, who can make predictions on a short (seasonally) and long-term (interannual) basis. 
Table 1

E-distances calculated on the first component corresponding to decadal periods 070-079 and 294-304 within years 1998-2004 (n.s. = not significant).

\begin{tabular}{|c|c|c|}
\hline Comparison & E-statistic test & $p$ \\
\hline 1998 vs. 1999 070_079 & 113.1 & $<0.01$ \\
\hline 1998 vs. 2000 070_079 & 213.2 & $<0.01$ \\
\hline 1998 vs. 2001 070_079 & 32.7 & $<0.01$ \\
\hline 1998 vs. 2002 070_079 & 20.08 & n.s. \\
\hline 1998 vs. 2003 070_079 & 66.04 & $<0.01$ \\
\hline 1998 vs. 2004 070_079 & 15.2 & n.s. \\
\hline 1999 vs. 2000 070_079 & 60.9 & $<0.01$ \\
\hline 1999 vs. 2001 070_079 & 216.9 & $<0.01$ \\
\hline 1999 vs. 2002 070_079 & 184.9 & $<0.01$ \\
\hline 1999 vs. 2003 070_079 & 289.9 & $<0.01$ \\
\hline 1999 vs. 2004 070_079 & 153.2 & $<0.01$ \\
\hline 2000 vs. 2001 070_079 & 113.8 & $<0.01$ \\
\hline 2000 vs. 2002 070_079 & 92.5 & $<0.01$ \\
\hline 2000 vs. 2003 070_079 & 158.4 & $<0.01$ \\
\hline 2000 vs. 2004 070_079 & 213.2 & $<0.01$ \\
\hline 2001 vs. 2002 070_079 & 7.7 & n.s. \\
\hline 2001 vs. 2003 070_079 & 14.9 & n.s. \\
\hline 2001 vs. 2004 070_079 & 19.4 & n.s. \\
\hline 2002 vs. 2003 070_079 & 21.3 & n.s. \\
\hline 2002 vs. 2004 070_079 & 14.2 & n.s. \\
\hline 2003 vs. 2004 070_079 & 47.1 & $<0.01$ \\
\hline 1998 vs. 1999 294_304 & 650.8 & $<0.01$ \\
\hline 1998 vs. 2000 294_304 & 5.6 & n.s. \\
\hline 1998 vs. 2001 294_304 & 6.77 & n.s. \\
\hline 1998 vs. 2002 294_304 & 5.2 & n.s. \\
\hline 1998 vs. 2003 294_304 & 22.5 & n.s. \\
\hline 1998 vs. 2004 294_304 & 142.5 & $<0.01$ \\
\hline 1999 vs. 2000 294_304 & 646.2 & $<0.01$ \\
\hline 1999 vs. 2001 294_304 & 609.9 & $<0.01$ \\
\hline 1999 vs. 2002 294_304 & 609.4 & $<0.01$ \\
\hline 1999 vs. 2003 294_304 & 522.4 & $<0.01$ \\
\hline 1999 vs. 2004 294_304 & 273.9 & $<0.01$ \\
\hline 2000 vs. 2001 294_304 & 8.6 & n.s. \\
\hline 2000 vs. 2002 294_304 & 5.07 & n.s. \\
\hline 2000 vs. 2003 294_304 & 21.5 & n.s. \\
\hline 2000 vs. 2004 294_304 & 143.9 & $<0.01$ \\
\hline 2001 vs. 2002 294_304 & 5.08 & n.s. \\
\hline 2001 vs. 2003 294_304 & 14.1 & n.s. \\
\hline 2001 vs. 2004 294_304 & 125.5 & $<0.01$ \\
\hline 2002 vs. 2003 294_304 & 15.5 & n.s. \\
\hline 2002 vs. 2004 294_304 & 125.3 & $<0.01$ \\
\hline 2003 vs. 2004 294_304 & 95.4 & $<0.01$ \\
\hline
\end{tabular}

Table 2

E-distances calculated on the first component corresponding to decadal periods from 060-069 to 101-110 and from 294-304 to 355-365, during 1999 and 2004 (n.s. = not significant).

\begin{tabular}{|c|c|c|}
\hline Comparison & E-statistic test & $p$ \\
\hline 1999 060_069 vs. 070_069 & 106.7 & $<0.01$ \\
\hline 1999 070_079 vs. 080_090 & 14.3 & n.s. \\
\hline 1999 080_090 vs.091_100 & 15.6 & n.s. \\
\hline 1999 091_100 vs. $101 \_110$ & 18.7 & n.s. \\
\hline 1999 294_304 vs. 305_314 & 419.5 & $<0.01$ \\
\hline 1999 305_314 vs. 315_324 & 188.7 & $<0.01$ \\
\hline 1999 315_324 vs. 325_334 & 351.3 & $<0.01$ \\
\hline 1999 325_334 vs. 335_344 & 15.6 & n.s. \\
\hline 1999 335_344 vs. 345_354 & 111.3 & $<0.01$ \\
\hline 1999 345_354 vs. 355_365 & 112.7 & $<0.01$ \\
\hline 2004 061_070 vs. 071_080 & 44.9 & $<0.01$ \\
\hline 2004 071_080 vs. 081_091 & 68.8 & $<0.01$ \\
\hline 2004 081_091 vs. 092_101 & 54.7 & $<0.01$ \\
\hline 2004 092_101 vs. $102 \_111$ & 22.03 & n.s. \\
\hline 2004 295_305 vs. 306_315 & 79.9 & $<0.01$ \\
\hline 2004 306_315 vs. $316 \_325$ & 22.7 & n.s. \\
\hline 2004 316_325 vs. 326_335 & 26.3 & $<0.01$ \\
\hline 2004 326_335 vs. 336_345 & 240.3 & $<0.01$ \\
\hline 2004 336_345 vs. 346_355 & 303.3 & $<0.01$ \\
\hline 2004 346_355 vs. 356_366 & 67.8 & $<0.01$ \\
\hline
\end{tabular}

The statistical methodology applied in this study could be used in all cases where remotely-sensed historical time series are available to evaluate quantitatively the data. The benefit of this approach is the objectivity of the assessment, which permits meaningful interpretation.

The operational predictive tool developed in this study is therefore helpful to control the Pelagos Sanctuary, as well as the quality of information provided on trophic levels which influences the marine food web. The knowledge of Pelagos ecosystem status, evolution and trends are vital to maintain a healthy, sustainable and productive environment.

In general the numerical operational tool developed in this study generates the information required to assess and respond to ecosystem changes. The forecast statistical procedure, based on factual evidence, can assist MPA managers with the identification of new environmental concerns and the evaluation of trends over time. In the long-term, multidisciplinary research and monitoring provides decision-makers with particularly useful information.

\section{Conclusions}

- A statistical approach to the analysis of the remotely sensed chl field has been proposed.

- The results of this statistical analysis allowed visualisation of $c h l$ biomass within a large geographic area and over a multi-annual period.

- The analysis highlighted recurrent, seasonal variations of chl, with the presence of a major peak in spring. Secondary peaks reported for the planktonic field of the Western Mediterranean by Margalef (1985) were not visible on the data reported.

- Fuller understanding is needed to enable robust links to be made between phytoplankton production and levels in relation to secondary consumers, particularly zooplankton.

- The present approach should also foresee the integration of zooplankton (Meganyctiphanes norvegica) biomass distribution abundance and seasonality data, collected within the Pelagos Sanctuary, to provide additional insight for effective management of this high conservation value pelagic MPA.

- The management of the Sanctuary should foresee a long term monitoring of physical and biological features and the understanding of the interaction between biotic and abiotic components and their influence on ecosystem structure and species distribution.

\section{Acknowledgements}

The authors would like to thank SEaWiFS project and the Distributed Active Archive Centre at the Goddard Space Flight Centre, Greenbelt, MD 20771 for the production and distribution of the data used for this study. These activities are sponsored by NASA's Mission to Planet Earth Program.

The authors thank Dr. B. Monger for his precious support in imagery analysis.

\section{Appendix A. Satellite data processing}

In the high resolution mode (Local Area Coverage; LAC), the Ocean Colour passive sensor SeaWiFS has a temporal resolution of 2 days (although a given target can be imaged daily, in different parts of the scan), a scan width of $58.3^{\circ}$, a scan coverage of $2800 \mathrm{~km}$, a nominal resolution of $1.13 \mathrm{~km}$ at nadir, and a tilt capability between $-20^{\circ}$ and $+20^{\circ}$. The sensor detects 8 bands of the visible and near infrared parts of the electromagnetic spectrum. L1A products contain all the raw Level 0 data (raw radiance counts from all bands plus spacecraft and instrument telemetry) with calibration and navigation data appended (Feldman, 2003). 
The original data acquired from the Goddard Space Flight Centre (NASA) were Level 1A (L1A) data in High Resolution Picture Transmission (HRPT) format, stored in Hierarchical Data Format (HDF).

These data were converted to Level 2 (L2) geophysical products, including chl, by means of the algorithms set available in the SeaWiFS Data Analysis System (SeaDAS) software package (Fu et al., 1998), with additional modifications described by Mélin et al. (2000) and Sturm and Zibordi (2002). During the conversion process, the L1A data first undergo atmospheric correction and are then converted from top-of-the-atmosphere radiances to normalised water-leaving radiances $(\mathrm{nLw})$.

\section{Appendix B. Energy distance statistics}

Energy distance (E-distance), refers to a statistical distance between probability distributions.

E-distance $(D)$ satisfies all axioms of a metric, thus energy distance characterises the equality of statistical distributions, that is to say: $D(F, G)=0$ if and only if $F=G$.

E-distance for statistical applications was introduced in 1985 by Gábor J. Székely, in analogy with the notion of Newton's potential energy. The idea was to consider statistical observations as heavenly bodies governed by a statistical potential energy, which is zero only when an underlying statistical null hypothesis $\left(H_{0}: D=0\right)$, is true. Energy statistics are therefore functions of distances between statistical observations.

The software used is RGUI free software ( $R$ Development Core Team, 2004) and in particular multi-sample energy statistics included in Energy package. In particular, we used the edist() command to calculate the E-distance between clusters (images) and eqdist.etest() to perform the nonparametric multisample $\mathrm{E}$ statistic (energy) test for equality of multivariate distribution.

The command edist() provides a vector containing the pairwise two-sample multivariate E-statistics for comparing clusters or samples, with the related probability (significance). The E-distance between clusters is computed from the original pooled data, stacked in matrix $X$, where each row is a multivariate observation, or from the distance matrix $X$ of the original data. The first (sizes[1]) rows of the original data matrix are the first sample, the next (sizes[2]) rows are the second sample, etc. The command eqdist.etest() performs the nonparametric multisample E-statistic (energy) test for equality of multivariate distributions. The test is implemented by nonparametric bootstrap, an approximate permutation test with $\mathrm{R}$ replicates.

We refer the interested reader to further explore these topics, directly to the website that makes available all necessary documentation about the 'energy' package (version 1.6.2) and accessible at: http://cran.r-project.org/.

\section{References}

Abdulla, A., Gomei, M., Maison, E., Piante, C., 2008. Status of marine protected areas in the Mediterranean Sea. IUCN, Malaga and WWF, France, p. 152.

Aguilar, A., 2000. Population biology, conservation threats and status of Mediterranean striped dolphins (Stenella coeruleoalba). J. Cetacean Res. Manag. 2, $17-26$.

Andersen, V., Prieur, L., 2000. One-month study in the open NW Mediterranean Sea (DYNAPROC experiment, May 1995): overview of the hydrobiogeochemical structures and effects of wind events. Deep-Sea Res. I 47 (3), 397-422.

Arnone, R., 1994. The temporal and spatial variability of chlorophyll in the western Mediterranean. In: La Violette, Paul E. (Ed.), Seasonal and interannual Variability of the Western Mediterranean Sea. In: Coastal and Estuarine Studies, American Geophysical Union, Washington, USA, pp. 195-225.

Astraldi, M., Bianchi, C.N., Gasparini, G.P., Morri, C., 1995. Climatic fluctuations, current variability and marine species distribution: A case study in the Ligurian Sea (north-west Mediterranean). Oceanol. Acta 18 (2), 139-149.

Astraldi, M., Gasparini, G., 1986. La circolazione costiera nel Mar Ligure orientale. Boll. Mus. Ist. Biol. Univ. Genova 52 (Suppl.), 317-331.
Astraldi, M., Gasparini, G.P., Sparnocchia, S., 1994. The seasonal and interannual variability in the Ligurian-Provencal Basin. In: La Violette, Paul E. (Ed.), Seasonal and Interannual Variability of the Western Mediterranean Sea. In: Coastal and Estuarine Studies, vol. 46. American Geophysical Union, Washington, USA, pp. 93-113.

Astraldi, M., Manzella, G., 1983. Some observations on current measurements on the East Ligurian shelf, Mediterranean Sea. Cont. Shelf Res. 2, 183-193.

Azzellino, A., Gaspari, S., Airoldi, S., Nani, B., 2008. Habitat use and preferences of cetaceans along the continental slope and the adjacent pelagic waters in the western LigurianSea. Deep Sea Res. A 55 (3), 296-323.

Azzellino, A., Panigada, S., Lanfredi, C., Zanardelli, M., Airoldi, S., Notarbartolo di Sciara, G., 2012. Predictive habitat models for managing marine areas: spatial and temporal distribution of marine mammals within the Pelagos Sanctuary (Northwestern Mediterranean Sea). Ocean Coast. Manag. 67, 63-74.

Barale, V., Jaquet, J.-M., Ndiaye, M., 2008. Algal blooming patterns and anomalies in the Mediterranean Sea as derived from the SeaWiFS data set (1998-2003). Remote Sens. Environ. 112, 3300-3313.

Barale, V., Panigada, S., Zanardelli, M., 2002. Habitat preferences of fin whales (Balaenoptera physalus) in the northwestern Mediterranean Sea: a comparison between in situ and remote sensing data. In: Proceedings of the 7th Thematic Conference 'Remote Sensing for Marine and Coastal Environments', Miami, FL, USA, 20-22/05/2002 (on CD-ROM, VERIDIAN, Ann Arbor, MI, USA, 2002).

Batisse, M., de Grissac, A.J., 1995. Marine Region 3: Mediterranean. In: A Global Representative System of Marine Protected Areas. Great Barrier Reef Marine Park Authority, The World Bank, The World Conservation Union (IUCN), pp. 77-104.

Bee Dagum, E., 2002. Analisi delle Serie Storiche. Modellistica, Previsione e Scomposizione. Springer-Verlag, Italia, p. 302. (Published in Italian).

Bérubé, M., Aguilar, A., Dendanto, D., Larsen, F., Notarbartolo di Sciara, G., Sears, R., Sigurjonsson, J., Urbàn, R., Palsbøl, P., 1998. Population genetic structure of North Atlantic, Mediterranean Sea and Sea of Cortez fin whales, Balaenoptera physalus (Linnaeus, 1758); analysis of mitochondrial and nuclear loci. Mol. Ecol. 7, 585-599.

Béthoux, J.P., Gentili, B., Tailliez, D., 1998. Warming and freshwater budget change in the Mediterranean since the 1940s, their possible relation to the greenhouse effect. Geophys. Res. Lett. 25 (7), 1023-1026.

Buffoni, G., Falco, P., Griffa, A., Zambianchi, E., 1997. Dispersion processes and residence times in a semi-enclosed basin with recirculating gyres. An application to the Tyrrhenian Sea. J. Geophys. Res. 102 (C8), 18699-18713.

Bunker, A.F., 1972. Wintertime interactions of the atmosphere with the Mediterranean Sea. J. Phys. Oceanogr. 2, 225-238.

Buongiorno Nardelli, B., Santoleri, R., Marullo, S., Guarracino, M., 2007. La temperatura superficiale del Mar Mediterraneo negli ultimi 21 anni: analisi delle misure satellitari (Mediterranean Sea SST skin within the last 21 Years: Satellite Data Analyses). In: Carli, B., Cavarretta, G., Col acino, M., Fuzzi, S. (Eds.), Clima e Cambiamenti Climatici: le Attività di Ricerca del CNR. pp. 345-348.

Clark, C.W., Borsani, J.F., Notarbartolo di Sciara, G., 2002. Vocal Activity of Balaenoptera physalus, in the Ligurian Sea. Mar. Mamm. Sci. 18 (1), 286-295.

Colella, S., 2007. La produzione primaria nel Mar Mediterraneo da satellite: sviluppo di un modello regionale e sua applicazione ai dati SeaWiFS, MODIS e MERIS (Ph.D. Thesis), Università degli Studi di Napoli Federico II.

Cruzado, A., 1985. Chemistry of Mediterranean waters. In: Margalef, R. (Ed.), Western Mediterranean. Pergamon Press, Oxford, pp. 126-147.

Dagnino, I., 1978. On the transport of sediments along the western border of the Ligurian Sea. In: Atti II Congresso A.I.O.L, pp. 223-226.

De Maio, A., Moretti, M., Sansone, E., Spezie, G., Vultaggio, M., 1975. Su la circolazione superficiale e profonda nel Golfo di Genova. Ann. Ist. Univ. Nav. Napoli 43-44, 97-112.

Doglioli, A.M., Griffa, A., Magaldi, M.G., 2004. Numerical study of a coastal current on a steep slope in presence of a cape: the case of the Promontorio of Portofino. J. Geophys. Res. 109, C12033. http://dx.doi.org/10.1029/2004JC002422.

Esposito, A., Manzella, G., 1982. Current circulation in the Ligurian Sea. In: Nihoul, J. (Ed.), Hydrodynamics of Semi-Enclosed Seas. Elsevier Scientific Publishing Company, Amsterdam, pp. 187-204.

Feldman, G.C., 2003. Summary and Samples of SeaWiFS Operational Data, available at: http://seawifs.gsfc.nasa.gov/SEAWIFS/SOFTWARE/DATA_PRODUCTS.html.

Forcada, J., Aguilar, A., Hammond, P., Pastor, X., Aguilar, R., 1996. Distributionandabundanceof?nwhales(Balaenoptera physalus) in the western Mediterranean sea during the summer. J. Zool., London 238, 23-34.

Fu, G., Baith, K.S., McClain, C.R., 1998. SeaDAS: The SeaWiFS Data Analysis System. Proc. of the 4th Pacific Ocean Remote Sensing Conference, Quingdao (China), 28-31 Jul. 1998, pp. 73-79.

Gascard, J.-C., 1978. Mediterranean deep water formation, baroclinic instability and oceanic eddies. Oceanol. Acta 1 (3), 315-330.

Gordon, J.C.D., Matthews, J.N., Panigada, S., Gannier, A., Borsani, J.F., Notarbartolo di Sciara, G., 2000. Distribution and relative abundance of striped dolphins, and distribution of sperm whales in the Ligurian Sea cetacean sanctuary: results from a collaboration using acoustic monitoring techniques. J. Cetacean Res. Manag. 2, 27-36.

Harris, G.P., 1984. Phytoplankton Ecology. Chapman \& Hall, London, p. 384.

Jacques, G., 1990. L'oligotrophie du milieu pelagique de la Mediterranee occidentale:un paradigme que s'stompe? Bull. Soc. Zool. France 114 (3), 17-30.

Johnson, R.A., Wichern, D.W., 1982. Applied Multivariate Statistical Analysis. Prentice-Hall, Inc., Englewood Cliffs, NJ, p. 594.

Manzella, G.M.R., 1983. The Ligurian Sea dynamics and its time evolution, C.N.R. -I.S.D.G.M., Staz. Oceanografica La Spezia, T.R. 123, p. 55

Margalef, R., 1985. Western Mediterranean. Pergamon Press, Oxford, p. 363. 
Marullo, S., Guarracino, M., 2003. L'anomalia termica del 2003 nel Mar Mediterraneo osservata da satellite. In: Energia Ambiente e Innovazione Novembre-Dicembre 2003, ENEA.

McClain, C.R., Feldman, G.C., Hooker, S.B., 2004. An overview of the SeaWiFS project and strategies for producing a climate research quality global ocean bio-optical time series. Deep-Sea Res. II 51, 5-42.

Mélin, F., Bulgarelli, B., Gobron, N., Pinty, B., Tacchi, R., 2000. An integrated tool for SeaWiFS operational processing, European Commission, EUR 19576 EN.

Millot, C., 1990. The Gulf of Lions' hydrodynamics. Cont. Shelf Res. 10 (9-11), $885-894$.

Nezlin, N.P., Lacroix, G., Kostianoy, A.G., Djenidi, S., 2004. Remotely sensed seasona dynamics of phytoplankton in the Ligurian Sea in 1997-1999. J. Geophys. Res. 109, C07013. http://dx.doi.org/10.1029/2000JC000628.

Notarbartolo di Sciara, G., 1994. La cetofauna del bacino corso-ligure-provenzale: rassegna delle attuali conoscenze. Biol. Mar. Mediterr. 1 (1), 95-98.

Notarbartolo di Sciara, G., Agardy, T., Hyrenbach, D., Scovazzi, T., Van Klaveren, P., 2008. The Pelagos sanctuary for mediterranean marine mammals. Aquat. Conserv. 18, 367-391.

O'Reilly, J.E., Mueller, J.L., Mitchell, B.G., Kahru, M., Chavez, F.P., Strutton, P., Cota G.F., Hooker, S.B., McClain, C.R., Carder, K.L., Muller-Karger, F., Harding, L. Magnuson, A., Phinney, D., Moore, G.F., Aiken, J., Arrigo, K.R., Letelier, R., Culver, M., 2000. SeaWiFS postlaunch calibration and validation analyses Part 3. In: Hooker S.B. and Firestone E.R. (eds), SeaWiFS Postlaunch Technical Report Series, NASA Technical Memorandum 2000-2067892, Vol. 11.

Orsi Relini, L., Relini, G., Palandri, G., Relini, M., Garibaldi, F., Cima, C., Torchia, G., Costa, C., 1998. Notes on ecology of the Mediterranean krill, a mirror of the behaviour of Mediterranean fin whales. In: Evans, P.G.H., Parsons, E.C.M. (Eds.) European Research on Cetaceans 12. European Cetacean Society, Valencia, p. 119
R Development Core Team, , 2004. R: A Language and Environment for Statistical Computing. R Foundation for Statistical Computing, Vienna, Austria, ISBN: 3900051-07-0, Available at http://www.R-project.org.

Sardou, J., Etienne, M., Andersen, V., 1996. Seasonal abundance and vertical distribution of macroplankton and micronekton in the northwestren Mediterranean Sea. Oceanol. Acta 19 (6), 645-656.

Secretariat of the Convention on Biological Diversity (CBD), 2008. protected areas in today's world: their values and benefits for the welfare of the planet. Montreal, Technical Series no. 36, i-vii. p. 96.

Secretariat of the Convention on Biological Diversity (CBD), (2012). COP 8 Decision VIII/22 Marine and coastal biological diversity: enhancing the implementation of integrated marine and coastal area management. http://www.cbd.int/decision/cop/?id=11036 (last accessed 16.03.12).

Stocchino, C., Testoni, A., 1977. Nuove osservazioni sulla circolazione delle correnti nel MarLigure. Progetto finalizzato "Oceanografia e fondi marini”. Ist. Idogr. Mar. Genova, F.C. 1076, 1-13.

Sturm, B., Zibordi, G., 2002. SeaWiFS atmospheric correction by an approximate model and vicarious calibration. Int. J. Remote Sens. 23 (3), 489-501.

Szekely, G.J., Rizzo, M.L., 2004. The energy package. Version 1.0.1, License, GPL 2.0 or later, http://cran.r-project.org/.

Szekely, G.J., Rizzo, M.L., 2013. Energy statistics: A class of statistics based on distances. J. Statist. Plann. Inference 143 (8), 1249-1272.

World Data Base on Protected Areas (WDPA), 2012. World Database on Marine Protected Areas http://www.wdpa-marine.org/\#/countries/about [last accessed 16.03.12]. 